\title{
ОСМЫСЛЕНИЕ ХУДОЖЕСТВЕННОЙ КУЛЬТУРЫ: ЦЕННОСТНЫЙ И ПРАКСЕОЛОГИЧЕСКИЙ ПОДХОД
}

\section{UNDERSTANDING ARTISTIC CULTURE: A VALUE AND PRAXIOLOGICAL APPROACH}

\section{S. Petrova}

Summary: Art culture is aimed at learning about a person's inner world. This knowledge has a special cultural significance and purpose, it helps the formation of personality, the development of human individuality to a greater extent than any other «mechanism» of culture. The article says that only artistic culture can embody the unity of nature and culture, material and spiritual, objective and subjective. By engaging in artistic activity, a person learns the language of the «second reality», during which he selects actions and interprets them in the light of his aesthetic ideal. It allows people to explore the surrounding space and develop their spiritual world, significantly enriches their social experience and is a synthesized human skill that combines the ability to learn, create, communicate and navigate values. Thus, the artistic development of the world turns out to be an integrative activity, in which all other activities intersect.

Keywords: culture, artistic culture, values, activity, person, material, spiritual.
K ультура зачастую восприниматься исключительно как творчество, как некое новшество, как обновление, постоянная замена всего существующего чемто новым. Однако эта интерпретация является односторонней. В конце концов, культура, по существу имеет две основы. Она опирается на то, что повторяется в жизни человека и проявляется в уникальном обновлении, требует взаимодействия традиционного и творческого.

Культура одновременно существует в каждом времени и в каждом обществе как нечто статичное (как культурная среда или культурное наследие) и в то же время как нечто динамичное, постоянно развивающееся и совершенствующееся в результате творческой деятельности человека [2].

В связи с этим возникает вопрос о критериях релевантности культурных ценностей. Формальных критериев как таковых не существует, но интуитивно мы можем понять, что, с одной стороны, такая культура включает в себя те произведения, которые поднимают общечеловеческие проблемы, несут на себе печать вечного, вызывают живой отклик. Поэтому очень часто мы сталкиваемся с тем, что ценности прошлого могут быть отнесены к нынешней культуре с большим правом, чем
Петрова Софья Игоревна

Академия маркетинга и социально-информационных технологий, г. Краснодар

Sofya8888@yandex.ru

Аннотация: Художественная культура направлена на познание человека его внутреннего мира. Это знание имеет особое культурное значение и цель, оно помогает формированию личности, развитию индивидуальности человека в большей степени, чем любой другой «механизм» культуры. В статье говорится, что только художественная культура может воплотить единство природы и культуры, материальное и духовное, объективное и субъективное. Занимаясь художественной деятельностью, человек овладевает языком «второй реальности», во время которой отбирает поступки и интерпретирует их в свете своего эстетического идеала. Это позволяет людям исследовать окружающее пространство и развивать свой духовный мир, значительно обогащает их социальный опыт и является синтезированным человеческим навыком, сочетающим в себе способность учиться, творить, общаться и ориентироваться в ценностях. Таким образом, художественное развитие мира оказывается интегративной деятельностью, в которой пересекаются все другие виды деятельности.

Ключевые слова: культура, художественная культура, ценности, деятельность, человек, материальное, духовное.

то, что имеет современное происхождение. Критерием релевантности может быть и сам факт удовлетворение потребностей людей. Другими словами, если человек получает желаемый результат, потребляя, осваивая или производя какую-либо ценность, эта ценность принадлежит современной культуре.

Направленность деятельности сыграла важную роль в развитии идей о культуре. Праксиологический подход стал достаточно гибким и включал анализ почти всех возможных особенностей культуры (и даже аксиологическую интерпретацию, против которой он выступал раньше). Однако, как отмечают некоторые авторы, этот подход исчерпал свои возможности [4, с 415]. Его особенно критикуют ученые считающие культуру лишь одной из сфер жизни общества (наряду с экономикой, политикой и т.д.), включающую учреждения культуры, а также культурную инфраструктуру. С их точки зрения, основным недостатком деятельностного подхода является то, что культура, ее отличия от других аспектов общественной жизни остаются в тени, культурное полностью совпадает с социальным. Получается, что все, что есть в обществе, принадлежит культуре. Это не позволяет, по их мнению, изучать особенности культуры как от- 
дельной области социального существования, отличной от других областей бытия.

Мы считаем, что интерпретация культуры в каждом конкретном случае будет зависеть от цели употребления этого термина, контекста его использования. И все интерпретации должны дополнять и обогащать друг друга. Для нас, в рамках нашего исследования, наиболее значимыми будут аксиологический и деятельностный подходы. Именно в рамках этих подходов мы рассмотрим художественную культуру.

В современном обществе культура все чаще доказывает не только свою полезность, но и необходимость в самых разных областях. Например, такие социокультурные факторы, как качество рабочей силы и наукоемкие технологии, имеют решающее значение для экономики. Поэтому в рамках деятельностной интерпретации культуры предметом исследования являются такие ее проявления, как культура труда, корпоративная культура, культура быта, политическая культура и др.

Однако не все в жизни общества и человека можно измерить полезностью. Если исходить из этого, то выявляются слои, элементы культуры, которые можно определить как «бесполезные» и, в первую очередь, это художественная культура. Но именно эта часть культуры поднимает человека над уровнем полезности [1, с. 130152]. По мнению М.С. Кагана, художественная культура - независимая от культуры подсистема, которую нельзя однозначно отнести к материальной или духовной культуре. Разрушая традиционную «материальное/духовное» дихотомию он говорит о необходимости «третьей», художественной культуры, которая рождается в результате сочетания противоположностей. Это подлинное слияние, а не механическая связь материальной и духовной культур. Таким образом, в художественной культуре противоположности взаимопроникают и становятся недифференцированными. Только художественная культура может воплотить единство природы и культуры, материальное и духовное, объективное и субъективное. Именно это подлинное слияние приводит к незаменимости материальной формы в художественном образе и невозможности перекодирования ее духовного содержания.

Наряду с наукой художественная культура является одной из исторически развитых форм функционирования культуры. Теоретическое научное знание М.С. Каган определяет как «сознание культуры». Наука предоставляет культуре необходимую информацию о природе, обществе, человеке, мире, окружающей среде, в которой она функционирует и, в конечном счете, о себе, рассматриваемой словно со стороны, объективированной, в законах ее структуры, функционирования и развития. Художественная культура - это самосознание культуры.
Художественная культура отражает объективный мир так, как он преломляется культурой, становясь ее собственным отражающим типом. Таким образом, искусство - это творческое самопознание реального

человека, это «зеркало в которое человек может заглянуть, чтобы глубже, познать себя». Такое самопознание достигается удвоением реальности, дополнением реальной жизни человека воображаемой и в, этом контексте, художественная культура выступает как уникальный инструмент культуры, с помощью которого люди могут раздвинуть границы своего опыта. Этот процесс наблюдался на протяжении всей истории человечества [3].

Необходимость дублирования реальности возникает у человека одновременно с появлением самого человека, общества и культуры. Исторически сложилось так, что первоначально он реализовывался в мифотворчестве, а затем в художественной деятельности. Известно, что нет ни одной нации, которая не имела бы своих мифов, легенд и искусства. Это дублирование реальности начинается в детстве, когда ребенок, играя, рисуя, танцуя, осознает себя и соединяется с другими людьми, входя в общество.

Художественная культура направлена на познание человека его внутреннего мира. Это знание имеет особое культурное значение и цель, оно помогает формированию личности, развитию индивидуальности человека в большей степени, чем любой другой «механизм» культуры.

Мы согласны с мнением М.С. Кагана, что связь между культурой и человеком осуществляется через его деятельность, и поэтому структура культуры отражает структуру деятельности. В культуре существует несколько видов деятельности: познание, осмысление ценностей, трансформация реальности, общение людей и художественное постижение мира.

Занимаясь художественной деятельностью, человек овладевает языком «второй реальности», во время которой отбирает поступки и интерпретирует их в свете своего эстетического идеала. Это позволяет людям исследовать окружающее пространство и развивать свой духовный мир, значительно обогащает их социальный опыт и является синтезированным человеческим навыком, сочетающим в себе способность учиться, творить, общаться и ориентироваться в ценностях. Таким образом, художественное развитие мира оказывается интегративной деятельностью, в которой пересекаются все другие виды деятельности.

В свою очередь, художественная деятельность имеет обратное влияние. Степень овладения языком «второй реальности» характеризует степень формирования ху- 
дожественного потенциала. Последнее существенно воздействует на развитие гносеологического, аксиологического, творческого и коммуникативного потенциалов, а степень их развития уже опосредована формированием художественного потенциала. То есть чем больше человек способен узнать при помощи «второй реальности» о «первой», чем больше он общается с художественной культурой, тем больше она влияет на все другие аспекты его деятельности. И здесь нужно указать на ряд проблем. Во-первых, художественная культура не всегда оказывает положительное влияние на человека, а во-вторых, она может быть инструментом манипуляции.

Поскольку художественная культура является отражением всей культуры, структура художественной деятельности повторяет структуру всей человеческой деятельности.

Таким образом, художественная культура, сочетающая в себе материальный и духовный аспекты культуры, становится формой практического и духовного развития, представляет человеческую личность в ее уникальных качествах.

Есть три способа овладеть языком «второй реальноСти»:

1. Знакомство с произведениями искусства.

2. Приобретение знаний по истории и теории искусства.

3. Само художественное творчество [5. с. 180].

При этом распространено мнение, что важнейшей задачей общения человека с художественной культурой является формирование у него потребностей самостоятельно создавать художественные ценности. Но в сфере художественной культуры потребление также является творческим процессом, поскольку восприятие произведения искусства предполагает в какой-то степени соавторство творца и потребителя, способность последнего понять «вторую реальность» и спроецировать ее на окружающую жизнь. Способность понимать, что художник имел в виду под своей «второй реальностью», способность считать отражение жизни в системе художественных образов, как умение создавать эту «вторую реальность», составляют две стороны художественных способностей человека.

Итак, по мнению исследователей, понятие «художественная культура» обычно включает в себя следующие группы явлений:

1. Свойства социального субъекта, которые необходимы для художественной деятельности.

2. Деятельность социального субъекта по созиданию, распределению, освоению продуктов художественной культуры.

3. Продукты художественной культуры.

4. Учреждения, обеспечивающие создание, распространение и освоение продуктов художественной культуры.

Таким образом, аксиологический и деятельностный подходы важны в изучении художественной культуры. В первом случае особое внимание следует уделять качеству предлагаемых художественных ценностей. Однако определить это качество довольно сложно, так как художественная ценность отличается от всех других видов ценностей иллюзорным характером мира образов, создаваемых в искусстве. Во всех других сферах ценностное сознание фиксирует для человека значение различных форм реальности.

Художественная культура утверждает мнимость, воображаемую природу своих образов. Художественная ценность произведения определяется его духовным содержанием, которое появляется в идеальном слое нереальных образов, и только затем адекватностью его материального воплощения во внешней форме произведения [1, с. 239].

Деятельностный подход позволяет проследить процесс развития сущностных сил человека и многое понять о нем как о личности. Художественная деятельность - социальна по форме, но индивидуальна по содержанию. Процесс овладения художественных ценностей человеком индивидуален и требует от людей разных усилий. Поэтому невозможно установить универсальные критерии оценки этих видов деятельности и, самое главное, их результатов. Они могут быть лишь признаны большей или меньшей частью общества.

\section{ЛИТЕРАТУРА}

1. Каган М.С. Философия культуры. СПб.: Петрополис. 1996. 415с.

2. К Келле В.Ж., Ковальзон М.Я. Теория и история (Проблемы теории исторического процесса). М.: Политиздат. 1981. 290 с.

3. Петров И.Ф. Духовный кризис как следствие рационализации культурно-исторического развития // Казачество. 2019. № 41 (5). С. $41-47$.

4. Философия культуры. Становление и развитие / Под ред. М.С. Кагана, Ю.В. Перова, В.В. Прозерского, Э.П. Юровской. СПб.: Лань. 1998. 448 с.

5. Человек в мире художественной культуры / Отв.ред. Ю.У. Фохт-Бабушкин. М.: Наука. 1982. 336с. 